\title{
CHẤT LƯợNG GIẤC NGỦ Ở BÊ̂NH NHÂN HộI CHỨNG ỐNG CỔ TAY ĐƯợC ĐIỀUU TRỊ PHẪU THUẬT TẠI BỆNH VIỆN ĐẠI HỌC Y HÀ NộI
}

Đỗ Văn Minh' ${ }^{1,2}$

\section{TÓM TẮT}

Mục tiêu: Đánh giá chất lượng giấc ngủ ở người bệnh bị hội chứng ống cổ tay được điêu trị phấu thuật tại Bệnh viện Đại học Y Hà Nội. Đối tượng và phương pháp nghiên cứu: Nghiên cứu tiến cứu 72 người bệnh bị hội chứng ống cổ tay tiên phát cả 2 bên, được mố cắt dây chằng ngang giải ép thần kinh giữa 2 bên trong 1 lần mổ tại khoa chấn thương chinh hình và y học thể thao Bệnh viện Đại học Y Hà Nội trong thời gian từ tháng 6 năm 2019 đến hết tháng 12 năm 2020. Tất cả người bệnh đánh giá mức độ nặng của triệu chứng và chức năng của bàn tay bằng thang điểm Boston, đánh giá chất lượng giấc ngủ bằng thang điểm Pittsburgh Sleep Quality Index (PSQI) ở thời điểm trước mổ và các thời điểm 3 tháng, 6 tháng sau mổ. Kết quả: Điểm PSQI trước mổ cho biết tất cả các bệnh nhân đều có tình trạng rối loạn giấc ngủ mức đồ năng. Chất lượng giấc ngủ của người bệnh sau mổ có sự cải thiện có ý nghĩa thống kề với điểm PSQI trước mổ có giá trị 14 (13-16) giảm xuống còn 9 (8-11) ở thời điểm 3 tháng và xuống còn 4 (4-5) ở thời điểm 6 tháng sau mổ. Mức độ nặng của triệu chứng và chức năng bàn tay cũng cải thiện tương tự. Kết luận:Phẫu thuật giải ép thânn kinh giữa không chỉ cải thiện triệu chứng, chức năng bàn tay mà còn cải thiện chất lượng giấc ngủ cho người bệnh hội chứng ống cổ tay.

Tư khóa: Hội chứng ống cổ tay, chất lượng giấc ngủ, phẫu thuật, Bệnh viện Đại học Y Hà Nội.

\section{SUMMARY}

\section{SLEEP QUALITY IN PATIENTS WITH CARPAL TUNNEL SYNDROME} UNDERGOING SURGICAL TREATMENT AT HANOI MEDICAL UNIVERSITY HOSPITAL

Objectives: To evaluate the sleep quality in patients with carpal tunnel syndrome undergoing surgical treatment at Hanoi Medical University Hospital. Materials and method: A prospective study of 72 patient with primary carpal tunnel syndrome of both handwho underwent both hand medial nerve decompression at Deparment of Orthopedics and Sports Medicine in Hanoi Medical University Hospital from June 2019 to December 2020. Boston questionnaire was used to assess the severity of symptoms and hand function and PittBurght Sleep Quality Index (PSQI) was to evaluate the sleep quality

\footnotetext{
${ }^{1}$ Trường Đại học Y Hà Nội,

${ }^{2}$ Bệnh viện Đại học Y Hà Nôi

Chịu trách nhiệm chính: Đổ Văn Minh

Email: mindovan@hmu.edu.vn

Ngày nhận bài: 2.8.2021

Ngày phản biện khoa học: 1.10.2021

Ngày duyệt bài: 7.10.2021
}

in all patients preoperatively and at 3 months postoperative ly and at 6 months postoperatively. Results:The preoperative PSQI scores indicated a severe sleep disoders in all patients. Postoperatively, sleep quality significantlyimproved with preoperative PSQI score of $14(13-16)$ and this decreased to 9 (811 ) at 3 months postoperatively and to 4 (4-5) at 6 months postoperatively. Symptomseverity and hand function scores decreased similarly. Conclusion: Medial nerve decompression surgery not only improved symptom severity and hand function but also improved sleep quality for carpal tunnel syndrome patients.

Keywords: Carpal tunnel syndrome, sleep quality, surgery, Hanoi Medical University Hospital

\section{I. ĐĂT VẤN ĐỀ}

Hội chứng ống cổ tay là tình trạng chèn ép thần kinh giữa tại vị trí trong ống cổ tay do nhiều nguyên nhân khác nhau gây nên. Rối loạn giấc ngủ là biểu hiện thường gặp của hội chứng ống cổ tay liên quan đến triêu chứng đau và tê tay do chèn ép thần kinh giữa. Người bệnh thường phàn nàn về các triệu chứng đau nhức, tê bì, buốt lạnh các ngón tay về đêm khiến cho người bệnh cần phải tỉnh giấc để xoa nắn, vẩy tay hoặc thay đổi vị trí của bàn tay. Khoảng $80 \%$ người bệnh mắc hội chứng ống cổ tay có tình trạng giảm chất lượng giấc ngủ ở các mức độ khác nhau [1].Đa số các bác sĩ lâm sàng chỉ quan tâm đến độ nặng của triệu chứng và chức năng của cổ bàn tay mà có phần xem nhẹ rối loạn chất lượng giấc ngủ ở người bệnh hội chứng ống cổ tay. Graham và cộng sự ghi nhận tê bàn tay về đêm là triệu chứng đặc trưng của hội chứng ống cổ tay và mục đích của điều trị là làm giảm các triệu chứng về đêm của người bệnh [2].Đã có nhiều nghiên cứu đánh giá ảnh hưởng tiêu cực của các bệnh mạn tính và hội chứng đau mạn tính đối với chất lượng giấc ngủ. Một số nghiển cứu đã bước đầu đánh giá đặc điểm rối loạn giấc ngủ ở người bệnh mắc hội chứng ống cổ tay và sự cải thiện chất lượng giấc ngủ ở người bệnh hội chứng ống cổ tay sau điều trị nội khoa hoặc điều trị ngoại khoa giải ép thần kinh giữa. Theo hiểu biết của chúng tôi, rối loạn giấc ngủ ở người bệnh hội chứng ống cổ tay chưa được quan tâm nhiều ở Việt Nam. Bởi thế chúng tồi tiến hành nghiên cứu này nhằm mục tiêu đánh giá chất lượng giấc ngủ ở người bệnh bị hội chứng ống cố tay được điều trị phẫu thuật tại Bệnh viện Đại học $Y$ Hà Nội. 
II. ĐỐI TƯợNG VÀ PHƯƠNG PHÁP NGHIÊN CỨU

2.1 Đối tượng nghiên cứu. Nghiên cứu 72 người bệnh bị hội chứng ống cổ tay tiên phát cả 2 bên, được mổ mở cắt dây chằng ngang giải ép thần kinh giữa 2 bên trong 1 lần mổ tại khoa chấn thương chỉnh hình và y học thể thao Bệnh viện Đại học Y Hà Nội trong thời gian từ tháng 6 năm 2019 đến hết tháng 12 năm 2020.

Tiêu chuẩn lựa chọn. Đối tượng nghiên cứu dựa vào tiêu chuẩn chẩn đoán hội chứng ống cổ tay và chỉ định điều trị phẫu thuật hội chứng ống cố tay.

Tiêu chuẩn chẩn đoán người bệnh mắc hội chứng ống cổ tay:

- Rối loạn cảm giác bàn tay theo vùng chi phối của thần kinh giữa, có thể có teo cơ mô cái.

- Có Nghiệm pháp Tinel và/ hoặc Phalen và/ hoặc Durkan dương tính.

- Giảm hoặc mất dẫn truyên thần kinh giữa đoạn qua ống cổ tay trên điện sinh lý thần kinh cớ.

- Có tăng kích thước thần kinh giữa đoạn sát bờ trên ống cổ tay trên siêu âm.

Chỉ định mổ cắt dây chằng ngang giải phóng thần kinh giữa trong hội chứng ống cổ tay:

- Người bệnh mắc hội chứng ống cổ tay ở mức độ trung bình, nặng hoặc rất nặng.

- Người bệnh mắc hội chứng ổng cổ tay ở mức độ nhẹ nhưng không đáp ứng với điều trị nội khoa ít nhất 3 tháng.

Tiêu chuẩn loại trừ:

- Hội chứng ống cổ tay thứ phát (sau gãy xương, do u xương, goute, viêm màng hoạt dịch gân gấp...)

- Người bệnh có bệnh lý chèn ép thần kinh ngoại biên khác kèm theo.

- Người bệnh có bệnh lý cột sống gây chèn ép rễ thần kinh.

- Người bệnh có bênh lý tâm thần kinh khác.

- Người bệnh có tiền sử chẩn đoán và điều trị rối loạn giấc ngủ trước đó.

- Người bệnh không mắc bệnh lý cần điều trị nội khoa hoặc ngoại khoa trong thời gian theo dối sau mổ (6 tháng sau mổ).

\subsection{Phương pháp nghiên cứu}

Thiết kế nghiên cứu mô tả theo dõi dọcmột loạt ca lâm sàng không có nhóm chứng.

Tất cả người bệnh đều được khám lâm sàng và đo điện sinh lý thần kinh chi trên trước mố, sau mổ 1 tháng, sau mổ 3 tháng và sau mổ 6 tháng. Tại các lần thăm khám người bệnh được đánh giá mức độ nặng của triệu chứng, chức năng bàn tay trước mổ và sau mổ dựa vào thang điểm Boston và đánh giá chất lượng giấc ngủ của người bệnh trước mổ và sau mổ dựa vào thang điểm Pittsburgh Sleep Quality Index (PSQI).

Thang điểmBoston gồm hai phần: 11 câu hỏi đánh giá mức độ nặng của triệu chứng (SSS) và 8 câu hỏi đánh giá chức năng của bàn tay (FSS). Mỗi câu hỏi có các lựa chọn trả lời riêng biệt được đánh số từ 1 đến 5 tương ứng với các mức độ từ nhẹ đến nặng. Điểm càng cao thì mức độ của triệu chứng càng nặng và chức năng bàn tay càng kém. Tổng điểm mức độ nặng của triệu chứng (SSS) và chức năng của bàn tay (FSS) được tính bắng tổng điểm của các câu hỏi thành phần. Điểm Boston bằng tổng của SSS và FSS của người bệnh.

Thang điểm Pittsburgh Sleep Quality Index (PSQI) là bộ câu hỏi dùng để định lượng chất lượng giấc ngủ trong vòng 1 tháng của người bệnh, gồm 24 câu hỏi được chia thành 7 cấu phần:chất lượng giấc ngủ, ngủ trễ, thời gian của giấc ngủ, thói quen ngủ hiệu quả, rối loạn giấc ngủ, dùng thuốc để ngủ, rối loạn chức năng ban ngày do buồn ngủ. Mối cấu phần có các lựa chọn trả lời riêng biệt được đánh số từ 0 đến 3 tương ứng với các mức độ từ không có vấn đề gì với giấc ngủ đến chất lượng giấc ngủ kém nhất. Tổng điểm PSQI được tính bằng tổng của các cấu phần (0-21 điểm). Nếu tổng điểm PSQI $\geq 5$ có nghĩa là người bệnh có chất lượng giấc ngủ kém. Tất cả các bệnh nhân của chúng tôi cả trong vòng 1 tháng trước mổ và sau mổ đều không dùng thuốc ngủ nên thành phần thứ sáu của thang điểm PSQI không được tính trong kết quả nghiên cứu này.

2.3 Xử lý số liệu: Số liệu được nhập liệu và phân tích bằng phẩn mềm SPSS 25.0. Các biến số phân loại được trình bày dưới dạng tỷ lệ. Các biến số liên tục được trình bày dưới dạng trung bình \pm độ lệch chuẩn hặc trung vị (độ trải giữa 25\%- 75\%).Sử dụng kiểm định KolmogorovSmirnov để đánh giá biến số có phân bố chuẩn. Các kiểm định Friedman, Wilcoxon được sử dụng để so sánh dữ liêuu trước mổ và sau mổ.

2.4 Đạo đức nghiên cứu: Người bệnh được khám và chỉ định mổ bởi hội đồng chuyên môn của Bênh viên Đại hơc $Y$ Hà Nôi. Đề cương nghiên cứu được phê duyệt bởi hội đồng đề tài khoa học của Trường Đại học Y Hà Nội. Các chuẩn mực đạo đức nghiển cứu y học được tôn trọng trong suốt quá trình thực hiện nghiên cứu.

\section{KẾT QUẢ NGHIÊN CỨU}

Nghiên cứu được tiến hành trên 72 người bệnh hội chứng ống cổ tay được điều trị phẫu thuật giải ép thần kinh giữa tại khoa chấn thương chỉnh hình và y học thể thao bệnh viện 
Đại học Y Hà Nội trong thời gian từ tháng 6 năm 2019 đến hết tháng 12 năm 2020, thời gian theo dõi sau mổ 6 tháng. Chúng tôi thu được một số kết quả sau:

- Đặc điểm chung của nhóm nghiên cứu

Bảng 1: Đặc điểm chung của nhóm nghiên cứu ( $n=72)$

\begin{tabular}{|c|c|c|c|}
\hline \multicolumn{2}{|c|}{} & $\begin{array}{c}\text { Số bê̂nh } \\
\text { nhần }\end{array}$ & $\begin{array}{c}\text { Tỷ lệ } \\
\text { \% }\end{array}$ \\
\hline \multirow{3}{*}{ Tuổi } & $<45$ & 11 & 15,3 \\
\cline { 2 - 4 } & $45-60$ & 55 & 76,4 \\
\cline { 2 - 4 } & $>60$ & 6 & 8,3 \\
\hline Giới & Nam & 0 & 0 \\
\hline
\end{tabular}

\begin{tabular}{|c|c|c|c|}
\hline & Nữ & 72 & 100 \\
\hline \multirow{3}{*}{ BMI } & Gầy & 12 & 16,7 \\
\cline { 2 - 4 } & Bình thường & 37 & 51,4 \\
\cline { 2 - 4 } & Tăng cân & 23 & 31,9 \\
\hline \multicolumn{2}{|c|}{$\begin{array}{c}\text { Thời gian khởi phát triệu } \\
\text { chứng đến khi phẫu thuật } \\
\text { (tháng) }\end{array}$} & $20,3 \pm 9,5$ \\
\hline
\end{tabular}

Toàn bộ 72 người bệnh trong nhóm nghiên cứu đều là nữ giới, tuổi trung bình của nhóm nghiên cứu là $52,3 \pm 8,7$ tuổi, đa số người bệnh có BMI trong giới hạn bình thường, thời gian trung bình từ khi có triệu chứng đến khi phẫu thuật khoảng 20,3 \pm 9,5 tháng.

- Thay đổi mức độ nặng của triệu chứng và chức năng bàn tay trước và sau mổ

Bảng 2: Thay đổi mức độ nặng của triệu chứng và chức năng bàn tay ( $n=144$ bàn tay)

\begin{tabular}{|c|c|c|c|c|}
\hline & & Trước mổ & Sau mổ 3 tháng & Sau mổ 6 tháng \\
\hline \multirow{2}{*}{ SSS } & Trung vị (độ trải giữa) & $31(29-35)$ & $18(16-23)$ & $9(7-11)$ \\
\hline & Trung bình \pm Độ lệch chuấn & $31,7 \pm 4,2$ & $19,5 \pm 4,8$ & $8,8 \pm 2,4$ \\
\hline \multirow{2}{*}{ FSS } & Trung vị (độ trải giữa) & $24(20-27)$ & $12(10-14,75)$ & $7(6-8)$ \\
\hline & Trung bình \pm Độ lệch chuấn & $23,4 \pm 4,4$ & $12,6 \pm 3,2$ & $7,0 \pm 1,5$ \\
\hline \multirow{2}{*}{$\begin{array}{l}\text { Điểm } \\
\text { Boston }\end{array}$} & Trung vị (độ trải giữa) & $56(50-60)$ & $30,5(27-38)$ & $16(13-18)$ \\
\hline & Trung bình \pm Độ lệch chuẩn & $55,1 \pm 6,4$ & $32,0 \pm 6,6$ & $15,7 \pm 3,5$ \\
\hline
\end{tabular}

Mức độ nặng của triệu chứng đánh giá bằng thang điểm SSS và chức năng bàn tay đánh giá bằng thang điểm FSS của người bệnh cải thiện một cách có ý nghĩa thống kê ở các thời điểm 3 tháng và 6 tháng sau mổ so với trước mổ với $\mathrm{p}<0,001$.

- Chất lượng giấc ngủ của người bệnh hội chứng ống cổ tay được điều trị phẫu thuật

\section{- Cải thiện chất lượng giấc ngủ chung sau mồ}

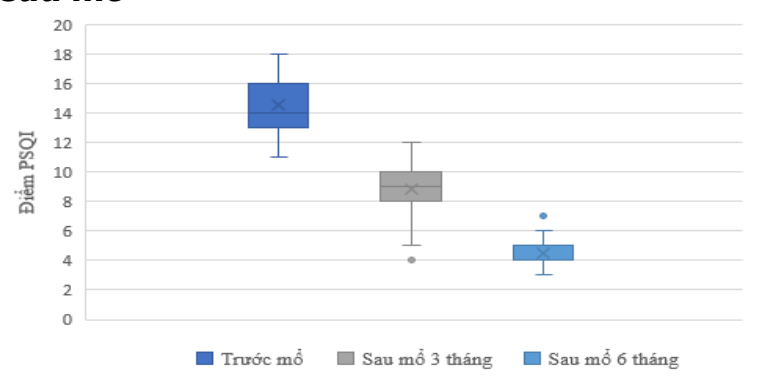

Biểu đồ 1: Cải thiện chât lượng giấc ngủ của người bệnh trước và sau mổ $(n=72)$

Điểm PSQI trước mổ cho thấy tất cả người bệnh đều có chất lượng giấc ngủ kém. Chất lượng giấc ngủ của người bệnh sau mổ có sự cải thiện có ý nghĩa thống kê vớiđiểm PSQI trước mố có giá trị 14(13-16) giảm xuống còn 9 (8-10) ở thời điểm 3 tháng và xuống còn 4 (4-5) ở thời điểm 6 tháng sau mổ với $\mathrm{p}<0.001$ (so sánh 6 mổ 3 tháng và sau mổ 6 tháng với trước mổ và sau mổ 6 tháng với sau mổ 3 tháng).

- Cải thiện các khía cạnh chất lượng giấc ngủ

Bảng 3: Cải thiện các khía cạnh chất lượng giấc ngủ trước và sau mổ (n=72)

\begin{tabular}{|c|c|c|c|c|c|c|}
\hline & \multicolumn{2}{|c|}{ Trước mố } & \multicolumn{2}{|c|}{ Sau mổ 3 tháng } & \multicolumn{2}{|c|}{ Sau mố 6 tháng } \\
\hline & $\begin{array}{c}\text { Trung vij } \\
\text { (Độ trải } \\
\text { giữa) }\end{array}$ & $\mathbf{p}^{*}$ & $\begin{array}{l}\text { Trung vị } \\
\text { (Độ trải } \\
\text { giữa) }\end{array}$ & $\mathbf{p}^{* *}$ & $\begin{array}{c}\text { Trung vij } \\
\text { (Độ trải } \\
\text { giữa) }\end{array}$ & $\mathbf{p}^{* * *}$ \\
\hline Chất lượng giấc ngủ & $2(2-3)$ & $<0,01$ & $2(1-2)$ & $<0,01$ & $1(1-1)$ & $<0,01$ \\
\hline Ngủ muộn & $2(2-3)$ & $<0,05$ & $2(1-2.5)$ & $<0,05$ & $1(1-2)$ & $<0,01$ \\
\hline Thời gian ngủ & $1(0-2)$ & $<0,05$ & $1(0-1)$ & $<0,05$ & $0(0-1)$ & $<0,01$ \\
\hline Thói quen ngủ hiệu quả & $3(3-3)$ & $<0,01$ & $2(2-2)$ & $<0,01$ & $1(1-1)$ & $<0,01$ \\
\hline Rối loạn giấc ngủ & $2(2-3)$ & $<0,01$ & $2(1-2)$ & $<0,01$ & $1(1-1,5)$ & $<0,01$ \\
\hline Rối loạn chức năng ban ngày & $3(2-3)$ & $<0,01$ & $2(1-2)$ & $<0,01$ & $1(0-1)$ & $<0,01$ \\
\hline
\end{tabular}

Tất cả 6 khía cạnh của chất lượng giấc ngủ đều có sự cải thiện có ý nghĩa thống kê ở các thời điểm 3 tháng và 6 tháng sau mổ so với trước mổ và ở thời điểm 6 tháng sau mổ so với trước mổ. 
(p*- so sánh sau mổ 3 tháng với trước mổ, $\mathrm{p}^{* *}$ - so sánh sau mổ 6 tháng với sau mổ 3 tháng và $\mathrm{p}^{* * *}$ - so sánh sau mổ 6 tháng với trước mổ).

\section{BÀN LUẬN}

Rối loạn giấc ngủ làm tăng nguy cơ mắc nhiều bệnh mạn tính và ảnh hưởng đến chất lượng cuộc sống của người bệnh. Gangwich và cộng sự đã chỉ ra rằng, những người ngủ < 5 giờ mỗi ngãy có nguy cơ cao mắc tăng huyết áp [3]. Sampaio và cộng sự ghi nhận, những người trên 65 tuổi mà có chất lượng giấc ngủ kém dễ bị trầm cảm và béo phì [4]. Ảnh hưởng của bệnh mạn tính và hội chứng đau mạn tính đến chất lượng giấc ngủ và thời lượng giấc ngủ đã được biết đến từ lâu và được nghiên cứu khá rộng rãi. Tuy vậy rối loạn giấc ngủ ở người bệnh hội chứng ống cổ tay mới chỉ được quan tâm trong vài năm trở lại đây. Các triệu chứng về giấc ngủ trong hội chứng ống cổ tay thường khai thác được bằng cách hỏi bệnh nên nó ít khi được định lượng và sử dụng như là một tiêu chuẩn khách quan để đánh giá kết quả điều trị.Hầu hết các thầy thuốc đều chú ý đến triệu chứng tại bàn tay của người bênh. Hiểu biết về tác động có hại của hội chứng ổng cổ tay lên chất lượng giấc ngủ giúp cho người thầy thuốc có thể đánh giá và điều trị người bệnh một cách toàn diện hơn. Patel và cộng sự chỉ ra rằng ở những người bệnh hội chứng ống cổ tay có mối liên quan có ý nghĩa thống kê giữa điểm PSQI với mức độ nặng của triệu chứng và chức năng bàn tay của người bệnh. Rubin và cộng sự ghi nhận, giữa kết quả điện sinh lý thần kinh giữa và chất lượng giấc ngủ của người bênh là hai biến độc lập không có liên quan gì đến nhau [5]. Karatas và cộng sự trong nghiên cứu của mình đã khẳng định, có mối liên hệ có ý nghĩa thống kê giữa chất lượng giấc ngủ của người bênh với mức độ nặng của triệu chứng và chức năng bàn tay đánh giá theo thang điểm Boston nhưng không có mối liên hê giữa kết quả điện sinh lý thần kinh giữa với chất lượng giấc ngủ của người bênh [6].

Trong nghiên cứu của chúng tôi, tất cả người bênh trong nhóm nghiên cứu đều là nữ giới. Từ kểt quả của điểm PSQI trước mổ nhận thây, tất cả người bệnh đều có chất lượng giấc ngủ kém. Một điều thú vị là trong nhóm này không có người bệnh nào sử dụng thuốc để ngủ trước mổ. Đây có thể coi là một đặc điểm riêng có của người bệnh trong nghiên cứu này.Kết quả nghiên cứu của chúng tôi đã khẳng định rằng, mức độ nặng của triệu chứng và chức năng của bàn tay có sự cải thiê̂n rõ rệt cùng với chất lượng giấc ngủ của người bênh ở các thời điểm 3 tháng và 6 tháng sau mổ so với thời điểm trước mổ. Chúng tôi cũng nhận thây, mức độ nặng của triệu chứng, chức năng bàn tay và chất lượng giẩc ngủ tiếp tục cải thiện một cách có ý nghĩa thống kê ở thời điểm sau 6 tháng sau mổso với thời điểm 3 tháng sau mổ. Sự cải thiện của chất lương giấc ngủ đánh giá theo thang điểm PSQI thể hiện trên tất cả các khía cạnh khác nhau của chất lượng giấc ngủ. Nhiều nghiên cứu đã đánh giá sự cải thiện về mức độ nặng của triêu chứng, chức năng bàn tay cũng như tốc độ dấn truyền thần kinh giữa sau mổ. Tại Việt Nam, Trần Trung Dũng và cộng sự ghi nhận sự cải thiện về triêu chứng, chức năng bàn tay cũng như tốc độ dẩn truyền thần kinh giữa sau 1 tháng, 3 tháng và 6 tháng sau mổ giải ép thần kinh giữa [7]. Tuy vậy, không có nhiều nghiên cứu đánh giá sự cải thiện chất lượng giấc ngủ ở người bệnh sau mổ giải ép thần kinh giữa. Tuliban và cộng sự khẳng định, phẫu thuật giải ép thần kinh giữa giúp cải thiện sớm vàhiệu quảchất lượng giấc ngủ của người bệnh một cách toàn diện.Cải thiện giấc ngủ nhận thấy sớm ngay sau 2 tuần sau mổ và tiếp tục cải thiện toàn diện sau 3 tháng sau mổ [8]. Okkesim và cộng sự ghi nhận phẫu thuật giải ép thần kinh giữa cải thiện cả về triệu chứng, chức năng bàn tay và chất lượng giấc ngủ cho người bệnh. Ở những người bệnh không có cải thiện về mức độ nặng của triệu chứng và chức năng bàn tay sau mổ cũng không có sự cải thiện về chất lượng giấc ngủ sau mổ. Ông đề xuất sử dụng PSQI như một thông số định lượng kết quả phẫu thuật [9]. Cả hai nghiên cứu trên đều ghi nhận, chất lượng giấc ngủ của người bệnh được cải thiện một cách toàn diện, trên tất cả các khía canh của chất lượng giấc ngư.

Điểm manh của nghiên cứu là được thực hiên tiến cứu với số lượng quan sát tướng đối lớn. Nhược điểm lớn nhất của nghiên cứu này là không có nhóm chứng để so sánh. Bên cạnh đó việc sử dụng bộ câu hỏi để đánh giá mức độ nặng của triệu chứng, chức năng bàn tay cũng như chất lượng giấc ngủ có thể gặp phải các sai số nhớ lại. Để kiểm soát sai số, chúng tôi đã phỏng vấn trực tiếp người bệnh, giải thích cặn kẽ từng câu hỏi để người bệnh hiểu và trả lời kết quả trung thực nhất, đồng thời yêu câu người bênh theo dõi sự cải thiên của triêu chứng nên những lần đánh giá sau mổ được thuận lợi và thu được kết quả sát với thực tế hơn.

\section{KẾT LUÂN}

Có sự cải thiện mức độ nặng của triệu chứng, 
chức năng của bàn tay cũng như chất lượng giấc ngủ của người bệnh sau mổ giải ép thân kinh giữa điều trị hội chứng ống cổ tay. Các khía cạnh của chất lượng giấc ngủ được cải thiện một cách toàn diện. Ngoài thang điểm Boston được khuyên dùng để đánh giá về mặt lâm sàng của mức độ nặng của triệu chứng và chức năng của bàn tay thì thang điểm PSQI nên được sử dụng như một tiêu chuẩn để đánh giá hiệu quả điêu trị hội chứng ống cổ tay.

\section{TÀI LIÊU THAM KHẢO}

1. Patel A., Culbertson M.D., Patel A. và cộng sứ. (2014). The negative effect of carpal tunnel syndrome on sleep quality. Sleep Disord, 2014, 962746.

2. Graham B., Regehr G., Naglie G. và cộng sự. (2006). Development and validation of diagnostic criteria for carpal tunnel syndrome. J Hand Surg, 31(6), 919-924.

3. Gangwisch J.E., Malaspina D., Boden-Albala B. và cộng sự. (2005). Inadequate sleep as a risk factor for obesity: analyses of the NHANES I.
Sleep, 28(10), 1289-1296.

4. Sampaio R.A.C., Sewo Sampaio P.Y., Yamada M. và cộng sứ. (2014). Self-reported quality of sleep is associated with bodily pain, vitality and cognitive impairment in Japanese older adults. Geriatr Gerontol Int, 14(3), 628-635.

5. Rubin G., Orbach H., Rinott M. và cộng sự. (2020). Relationship between electrodiagnostic findings and sleep disturbance in carpal tunnel syndrome: A controlled objective and subjective study. J Int Med Res, 48(2), 030006051986267.

6. Karatas G., Kutluk O., Akyuz M. và cộng sự. (2020). The effects of carpal tunnel syndrome on sleep quality. Ann Med Res, 27(1), 381.

7. Trung D.T., Ngoc T.M., Gia D.H. và cộng sự. (2019). Endoscopic carpal tunnel release surgery: a case study in Vietnam. $J$ Orthop Surg, 14(1), 149.

8. Tulipan J.E., Kim N., Abboudi J. và cộng sự. (2017). Prospective Evaluation of Sleep Improvement Following Carpal Tunnel Release Surgery. J Hand Surg, 42(5), 390.e1-390.e6.

9. Okkesim C.E., Serbest S., Tiftikçi U. và công sứ. (2019). Prospective evaluation of preoperative and postoperative sleep quality in carpal tunnel release. J Hand Surg Eur Vol, 44(3), 278-282.

\section{LIÊN QUAN GIỮA SÓNG TIỀN TÂM THU THẤT TRÁI VỚI CHỨC NĂNG TÂM TRƯƠNG THẤT TRÁI TRÊN SIÊU ÂM TIM Ở BÊ̂NH NHÂN ĐÁI THÁO ĐƯỜ'NG TYP 2}

\section{TÓM TẮT}

Mục tiêu: Tìm hiểu mối liên quan giữa sóng tiền tâm thu (TTT) thất trái với một số thông số chức năng tâm trương (CNTTr) thất trái trên siêu âm tim ở bệnh nhân (BN) đái tháo đường (ĐTĐ) typ 2. Đối tượng và phương pháp: Nghiên cứu mô tả, cắt ngang trên 60 BN ĐTÐ typ 2 và 30 người nhóm chứng tại khoa Nội tiết và Viện Tim mạch Bệnh viện Bạch Mai từ tháng 8/2020 đến tháng 8/2021. Các thông số nghiên cứu (NC) trên siêu âm tim: vận tốc và thời gian sóng TTT đo tại đường ra thất trái, kích thước và chức năng tâm trương thất trái, chỉ số Tei thất trái. Kết quả: Tỳ lệ sóng TTT thất trái là 90\% ở nhóm ĐTĐ, 93,3\% ở nhóm chứng ( $p: 0,600)$. Có $35 \%(21 B N)$ trong nhóm ĐTĐ có rối loạn CNTTr thất trái, trong đó $81 \%$ (17BN) là rối loạn CNTTr độ I, 19\% (4BN) là rối loạn CNTTr độ II. Có $6,7 \%$ (2BN) trong nhóm chứng có rôi loạn CNTTr thất trái (độ I). Đường kính thất trái tâm trương và thể tích thất trái tâm trương ở nhóm không có sóng TTT lớn hơn so với nhóm có sóng TTT

\footnotetext{
${ }^{1}$ Trường Đại học y Hà Nội

${ }^{2}$ Viện tim mạch Việt Nam, Bệnh viện Bạch Mai

Chịu trách nhiệm chính: Lê Thị Mai Sao

Email: lemaisaomlvp@gmail.com

Ngày nhận bài: 27.7.2021

Ngày phản biện khoa học: 30.9.2021

Ngày duyệt băi: 5.10 .2021
}

Lê Thị Mai Sao', Phạm Thị Hồng Thi²

$(p<0,05)$. Vận tốc sóng tiền tâm thu ở đường ra thất trái tương quan đồng biến với vận tốc sóng $A$ qua van 2 lá (rho $=0,413, p<0,001$ ), tương quan nghịch biến với tî lệ $E / A$ (rho $=-0,244, p=0,027$ ), tương quan đồng biến với chỉ số Tei thất trái (rho $=0,345$, $\mathrm{p}<0,005$ ).

Tư khóa: sóng tiền tâm thu thất trái; đái tháo đường typ 2; chức năng tâm trương thất trái; chỉ số Tei.

\section{SUMMARY \\ ASSOCIATION BETWEEN LEFT \\ VENTRICULAR'S PRESYSTOLIC WAVE AND LEFT VENTRICULAR DIASTOLIC FUNCTION \\ ON ECHOCARDIOGRAPHY IN TYPE 2 DIABETES MELLITUS PATIENTS}

Aims: Assess the association between left ventricular's presystolic wave and some of left ventricular diastolic function's values on echocardiography in types 2 diabetes mellitus patients. Patients and methods: we performed a descriptive cross - sectional study included 90 patients: 60 type 2 diabetes mellitus patients and 30 healthy subjects in endocrinology department - Bach Mai hospital and Vietnam National Heart institue. The researched values included: velocity and times of the presystolic wave mesured in LVOT, size and diastolic function of the left ventricular, Tei index. Results:The ratio of presystolic wave in LVOT is $90 \%$ in type 2 Diabetes 